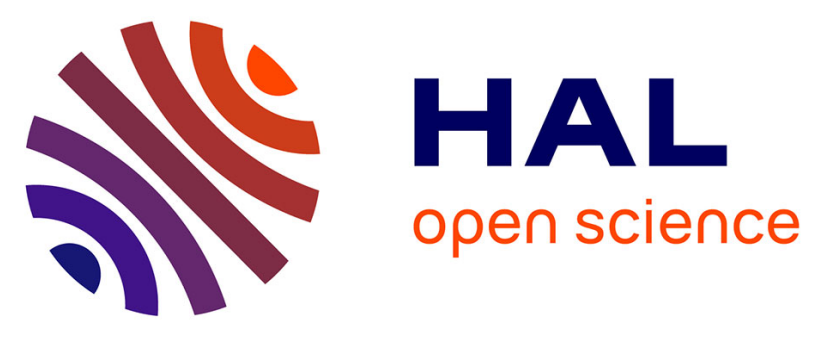

\title{
Discovery of novel N-methyl carbazole tethered rhodanine derivatives as direct inhibitors of Mycobacterium tuberculosis InhA
}

\author{
Mahamadhanif S. Shaikh, Ashish M. Kanheda, Chandrasekaran Balakumar, \\ Mahesh B. Palkar, Nikhil Agrawal, Christian Lherbet, Girish A \\ Hampannavar, Rajshekhar Karpoormath
}

\section{To cite this version:}

Mahamadhanif S. Shaikh, Ashish M. Kanheda, Chandrasekaran Balakumar, Mahesh B. Palkar, Nikhil Agrawal, et al.. Discovery of novel N-methyl carbazole tethered rhodanine derivatives as direct inhibitors of Mycobacterium tuberculosis InhA. Bioorganic and Medicinal Chemistry Letters, 2019, 29, pp.2338-2344. 10.1016/j.bmcl.2019.06.015 . hal-03038682

\section{HAL Id: hal-03038682 https://hal.science/hal-03038682}

Submitted on 3 Dec 2020

HAL is a multi-disciplinary open access archive for the deposit and dissemination of scientific research documents, whether they are published or not. The documents may come from teaching and research institutions in France or abroad, or from public or private research centers.
L'archive ouverte pluridisciplinaire HAL, est destinée au dépôt et à la diffusion de documents scientifiques de niveau recherche, publiés ou non, émanant des établissements d'enseignement et de recherche français ou étrangers, des laboratoires publics ou privés. 


\section{Discovery of novel $N$-methyl carbazole tethered rhodanine derivatives as direct inhibitors of Mycobacterium tuberculosis InhA}

Mahamadhanif S. Shaikh ${ }^{\mathrm{a}}$, Ashish M. Kanhed ${ }^{\mathrm{a} \$}$, Balakumar Chandrasekaran ${ }^{\mathrm{a} \$}$, Mahesh B. Palkar $^{\mathrm{a}}$, Nikhil Agrawal ${ }^{\mathrm{a}}$, Christian Lherbet ${ }^{\mathrm{b}}$, Girish A. Hampannavar ${ }^{\mathrm{a}}$ and Rajshekhar Karpoormath $^{\mathrm{a}^{*}}$

${ }^{a}$ Discipline of Pharmaceutical Sciences, College of Health Sciences, University of KwaZulu-Natal (UKZN), Westville, Durban 4001, South Africa.

${ }^{b}$ Laboratoire SPCMIB (UMR CNRS 5068), Université Paul Sabatier-Toulouse III, 118 route de Narbonne, 31062 Tou-louse Cedex 9, France ; ITAV-USR3505, CNRS, Université Paul Sabatier-Toulouse III, Toulouse, France.

*Corresponding author: karpoormath@ukzn.ac.za (R. Karpoormath) Fax: +27-312607792; Tel: +27-312607179, +27-721107207.

${ }^{\$}$ Contributed equally. 


\begin{abstract}
InhA (Enoyl-ACP reductase) plays a crucial role in the biosynthetic pathway of cell wall synthesis in Mycobacterium tuberculosis (Mtb). Isoniazid (INH) is an important firstline drug, which inhibits InhA. The rapid increase in resistance to INH and currently marketed drugs as well as emergence of MDR-TB and XDR-TB has complicated the diagnosis and treatment of Mtb with ever increasing threat to human kind. Herein, we report novel $N$-methyl carbazole derivatives as potential anti-TB compounds acting directly via InhA inhibition. All the synthesized final compounds were screened against Mtb virulent cell line $\mathrm{H}_{37} \mathrm{Rv}$ and investigated the InhA enzyme inhibition. Interestingly, compound 9e displayed promising inhibition $(91 \%)$ at $50 \mu \mathrm{M}$ concentration and $\mathrm{IC}_{50}$ of $2.82 \mu \mathrm{M}$ against InhA. To understand the ligand receptor interaction between compound $9 \mathrm{e}$ and InhA, molecular docking and molecular dynamics experiments were performed. The computational results were in agreement with the observed experimental data. Further, the cytotoxicity studies on mammalian cells revealed that all the compounds were safe.
\end{abstract}

\title{
Key words:
}

Tuberculosis; inh A inhibitor; Carbazole; Hybridization; GLIDE; Molecular dynamics. 
Tuberculosis (TB), a deadly infectious disease caused by the bacterium Mycobacterium tuberculosis (Mtb) and is the prime cause of mortality across the globe with increasing health and economic concerns especially in the developing nations. The WHO global TB report 2017 stated that more than 200 countries carry active TB infection claiming over 4,500 lives a day. To implement existing TB interventions, every year 2.5 billion USD is required. Even after spending huge resources and funds, 490000 cases of multiple drug resistance TB (MDR-TB) were reported in the year 2016. ${ }^{1}$ Further, the occurrence of coinfection with the Human Immunodeficiency Virus (HIV) together with the increase in global bacterial resistance has made $\mathrm{TB}$ as a re-emerging disease. ${ }^{2}$ The cell wall of the Mtb is unusually constructed with almost $60 \%$ of lipids (Mycolic acids, C60-C90 long $\alpha$-alkyl $\beta$ hydroxylated fatty acids) that are essential for the survival of this bacterium. In Mtb, EnoylACP reductase (InhA) of the type II fatty acid synthase (FAS-II) system is mainly engaged in the biosynthesis of these foremost components of mycobacterial cell wall. ${ }^{3}$

Isoniazid (INH) is a first line prodrug and Ethionamide (ETH), a second line prodrug used for the treatment of TB and exhibit their versatile action via the InhA inhibition. For active TB, these drugs are generally used along with rifampin, pyrazinamide and either ethambutol or streptomycin, whereas for latent TB, INH is used alone. ${ }^{4,5}$ Few reports have also mentioned the use of INH against other types of mycobacteria like M. kansasii, $M$. xenopi and M. avium. ${ }^{5}$ The use of INH in the HIV carrying TB patients is also well documented. ${ }^{6}$ INH and ETH being prodrugs, must be activated by some enzymes. A bacterial catalase-peroxidase enzyme in Mtb known as KatG activates $\mathrm{INH}^{7}$ whereas the monooxygenase ethA activates the ETH. ${ }^{8}$ These enzymes convert INH and ETH into respective acyl radicals which immediately couples with $\mathrm{NAD}^{+}$to form the NAD adduct. The formed adduct binds tightly to the active-site of InhA and inhibits the natural Enoyl-AcpM substrate and subsequently the action of FAS in Mtb. ${ }^{9}$ This action makes the InhA, one of the best drug target for the treatment of TB. The resistance to these most important drugs is reported mainly by the mutation in KatG and ethA in Mtb leading to the inability to activate these prodrugs for their action. ${ }^{7}$ Thus, the development of resistance to several anti-TB drugs including INH creates urgency for the discovery of new anti-TB agents.

The synthesis of novel carbazole derivatives and the investigation of their chemical and biological behaviour have gained importance in recent decades for their biological, 
medicinal and photoelectrical applications. Carbazole analogs from both natural and synthetic origin are known to display wide range of pharmacological properties such as anticancer, antibacterial and anti-TB activity. ${ }^{10,11}$ Similarly, literature indicated that the molecular manipulation of rhodanine moiety resulted in potent compounds that exhibited a wide spectrum of biological activities such as antimicrobial (including multidrug-resistant clinical isolates), anti-TB (III, Fig. 1), antifungal, antidiabetic, anti-HIV and anticancer. ${ }^{12,13}$ Literature also suggested that the rhodanine moiety is an important fragment for antimicrobial activity. ${ }^{14}$ Previously, $N$-methyl carbazole clubbed 1,2,3-triazoles (I, Fig. 1) were reported as promising anti-mycobacterial agents. ${ }^{15}$

We are also aware of rhodanine moiety is classified into a substantial pan-assay interfering compound (PAINS) that might confound the assay as well as may lead to apparent activity results. ${ }^{16,17}$ The two main reasons reported for promiscuous behavior were a) Formation of aggregates that non-specifically interact with the target which interferes with biochemical assay and can be countered by performing the assays under high-detergent conditions. ${ }^{18,19}$ b) Undergo facile reaction with nucleophiles via Michael addition to the exocyclic double bonded sulfur, which provides high density of interaction sites for polar interactions and hydrogen bonds. ${ }^{20}$ In order to identify PAINS and triage reactive compounds, Dahlin et al. suggested two general approaches, namely knowledge-based and experimentalbased methods. The knowledge-based strategies included substructure filters, literature and database searches, and consulting of experienced medicinal chemists, while the experimentalbased strategies included mechanistic experiments, thiol-based probes and multiple types of counter-screens. ${ }^{21}$

However, the concept of PAINS was countered by some researchers as indicated in recent literature reports that the criteria's defining PAINS should not be considered as a general criterion to exclude from screening compounds containing rhodanines and was suggested that some special criteria such as target affinity and selectivity should be employed. ${ }^{20,22}$ Thus some researchers still consider rhodanines as privileged heterocycles and building blocks for optimization and transformation into related simplified analogues and fused heterocycles. The Michael acceptor functionality as well as low selectivity must be confirmed experimentally and should not be just based on the presence of conjugated $\alpha, \beta$ unsaturated carbonyl. The positive aspects of Michael acceptors and multitarget properties must be taken into consideration. ${ }^{22}$ Compounds showing potential biomolecular binding properties could be further exploited in a useful way. It should be noted that the marketed 
drugs like pioglitazone used for diabetes mellitus type $2^{23}$ and epalrestat for diabetic neuropathy contain rhodanine scaffold as core moiety, while epalrestat specifically contains ene-rhodanine moiety. ${ }^{24}$ Further, rhodanine analogs have been recently reported for various pharmacological activities in peer-reviewed medicinal chemistry journals. ${ }^{25-29}$

Earlier, our research group has reported a series of $N$-methyl carbazolo-thiazole hybrid molecules (II, Fig. 1) as antimycobacterial agents against the virulent cell line of TB and displayed moderate activity with a good cytotoxicity profile on mammalian Vero cell line. ${ }^{10}$ Keeping in mind the activity profiles of those molecules, we envisaged to structurally modify them to achieve better antimycobacterial activity. Hence, we attempted to synthesize novel $N$-methyl carbazole tethered rhodanine derivatives (Fig. 1) using molecular hybridization approach.

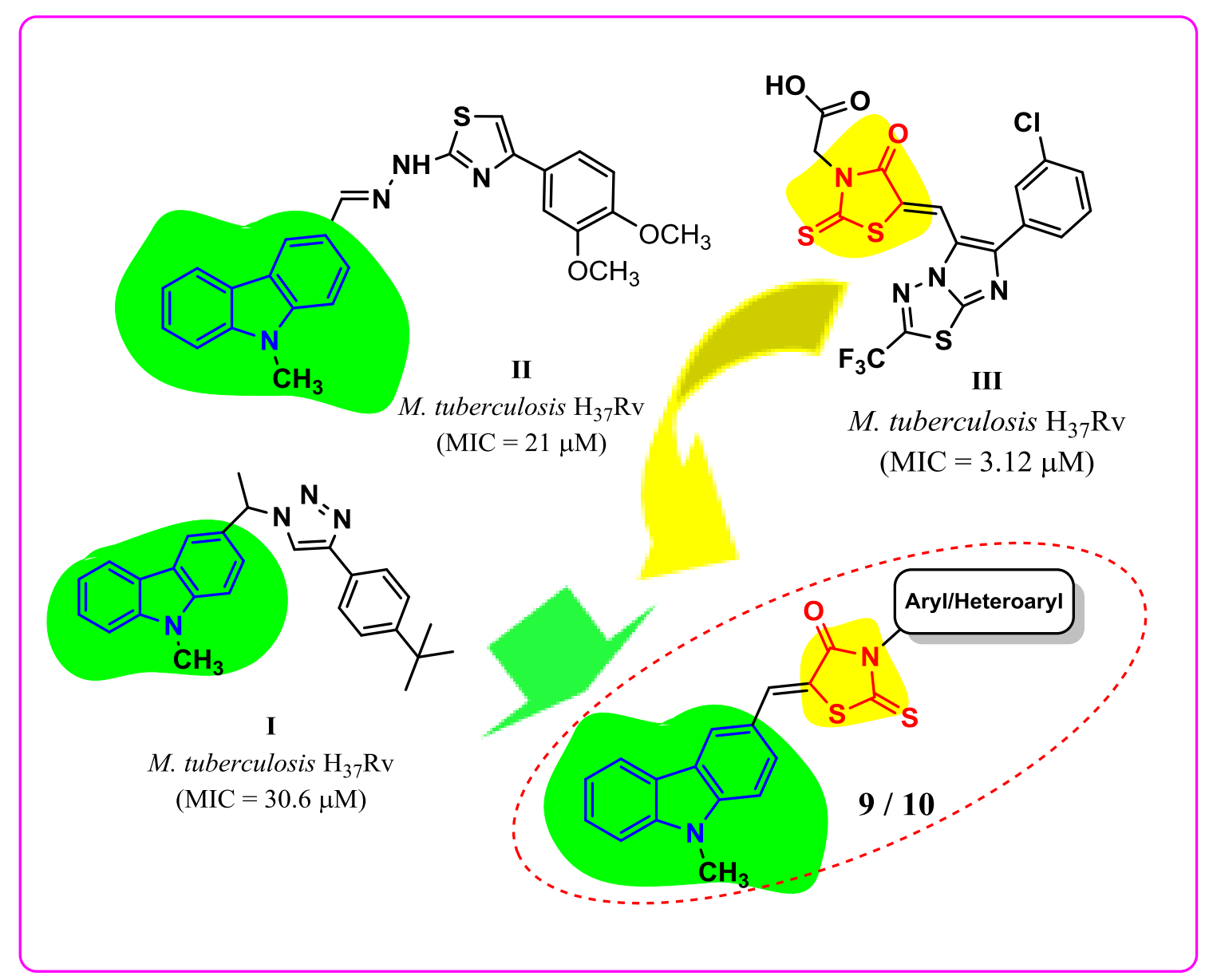

Fig. 1. Design of $N$-methyl carbazole tethered rhodanine derivatives using molecular hybridization approach.

The synthesis of $\mathrm{N}$-methyl carbazole tethered rhodanine derivatives 5-((9-methyl- $9 \mathrm{H}$ carbazol-6-yl)methylene)-3-(substituted phenyl)-2-thioxothiazolidin-4-one) (9a-9l) and 2-((9- 
methyl-9H-carbazol-6-yl)methylene)-4-(5-substituted phenyl-1,3,4-thiadiazol-2-yl)-5-thioxothiazolidin-4-one) derivatives (10a-10f) was achieved through an efficient and versatile synthetic route as illustrated in Scheme 1. In order to practically obtain the hybrid compounds, we first attempted the reactions by conventional method i.e. reflux in ethanol with a catalytic amount of piperidine for $24 \mathrm{~h}$, but this resulted in very poor yields (10-18\%). In order to achieve higher yields, these reactions were carried out under controlled microwave irradiation (CEM Discover, Explorer-12 Hybrid, Microwave conditions: $80{ }^{\circ} \mathrm{C}$, $30 \mathrm{~min}$ at $150 \mathrm{psi}$ ) which resulted in the corresponding carbazolyl substituted rhodanine derivatives 9a-9l and 10a-10f in considerably good yields (48-79\%).

Various rhodanine derivatives i.e. 3-substituted-phenyl-2-thioxothiazolidin-4-one (3a31) and 3-(5-substituted phenyl)-1,3,4-thiadiazol-2-yl)-2-thioxothiazolidin-4-one (5a-5f) were prepared as per the earlier reported method ${ }^{30}$ and were coupled to the $3^{\text {rd }}$ position of the carbazole ring to yield final compounds 9a-9l and 10a-10f. Synthesis of various substituted rhodanine derivatives was achieved by reacting bis(carboxylmethyl) trithiocarbonate (1) with appropriately substituted aromatic/heteroaromatic amines (2a-2l) and 5-substituted phenyl1,3,4-thiadiazol-2-amines (4a-4f) to obtain the desired intermediates $\mathbf{3 a - 3 1}$ and $\mathbf{5 a - 5 f}$, respectively. These intermediates were characterized and confirmed based on IR, ${ }^{1} \mathrm{H}-$ and ${ }^{13} \mathrm{C}-\mathrm{NMR}$ data. In IR spectra, the appearance of $1757-1676 \mathrm{~cm}^{-1}$ for $\mathrm{C}=\mathrm{O}$ (carbonyl), 1180$1100 \mathrm{~cm}^{-1}$ for $\mathrm{C}=\mathrm{S}$ and the absence of carboxylic acid group supported the formation of compounds 3a-3l and 5a-5f. This was further substantiated from the ${ }^{1} \mathrm{H}-\mathrm{NMR}$ spectrum, which showed the presence of a very distinct singlet at $\delta 4.4-4.17 \mathrm{ppm}$ for $-\mathrm{CH}_{2}$ - (methylene), while various aromatic/hetero-aromatic proton signals were observed between $\delta$ 8.53-6.40 ppm. In the ${ }^{13} \mathrm{C}-\mathrm{NMR}$ spectrum, the most characteristic carbon signals $\left(\underline{\mathrm{C}}=\mathrm{S}, \underline{\mathrm{C}}=\mathrm{O}\right.$ and $\left.\underline{\mathrm{CH}}_{2}\right)$ appeared at around $\delta$ 206.45-197.25, 173.94-168.04 and 38.85-36.4 ppm respectively, thus confirming the formation of the rhodanine nucleus. Synthesis of 9-methyl carbazole (7) was achieved by $N$-methylation of commercially available carbazole (6) with iodomethane and sodium hydride and its formation was confirmed by the absence of N-H stretching (IR) and appearance of N-methyl protons $\left({ }^{1} \mathrm{H}-\mathrm{NMR}\right)$. Further, Vilsmayer-Hack formylation of 9methyl carbazole (7) in the presence of $\mathrm{POCl}_{3}$ and DMF yielded 9-methyl-carbazole-3carbaldehyde (8) in good yield and was confirmed by the presence of carbonyl stretching (IR) and appearance of -Cㅡㅇ proton $\left({ }^{1} \mathrm{H}-\mathrm{NMR}\right)$. 


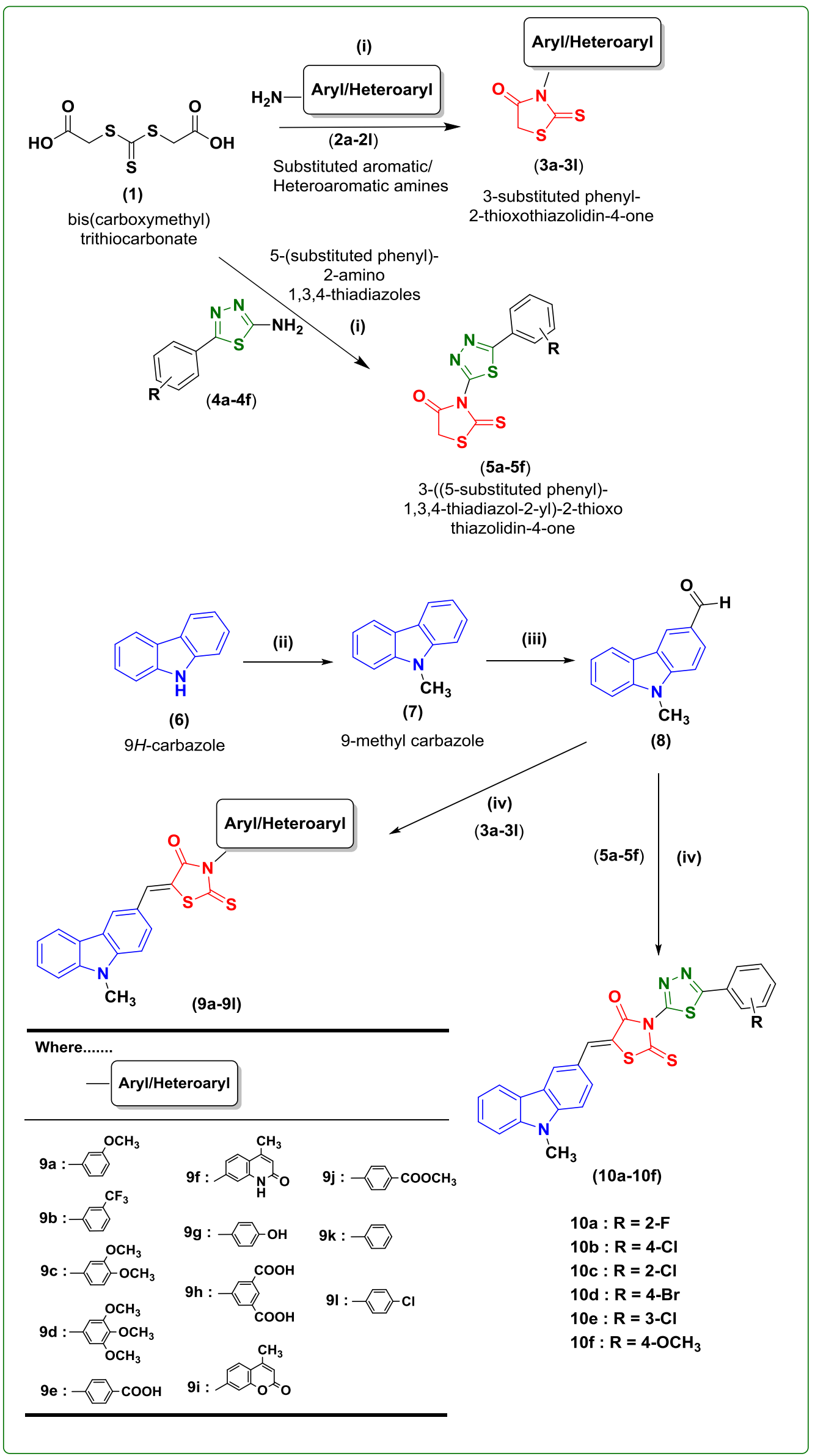


Scheme 1. Reagents and conditions: (i) bis(carboxymethyl) trithiocarbonate, substituted aromatic/heteroaromatic amines (2a-2l and 4a-4f), $\mathrm{H}_{2} \mathrm{O}$, reflux, $100{ }^{\circ} \mathrm{C}, 12-19 \mathrm{~h}$; (ii) DMF, $\mathrm{NaH}, \mathrm{CH}_{3} \mathrm{I}$, stir, RT, $5 \mathrm{~h}$; (iii) $\mathrm{POCl}_{3}$, DMF, $0{ }^{\circ} \mathrm{C}$, stir, $90{ }^{\circ} \mathrm{C}, 6 \mathrm{~h}, \mathrm{Na}_{2} \mathrm{CO}_{3}$; (iv) Compound 8 , rhodanine derivatives (3a-3l and 5a-5f), piperidine, ethanol, microwave irradiation, 30 mins, $80{ }^{\circ} \mathrm{C}, 150$ psi.

The final hybrids 9a-9l and 10a-10f were obtained by Knoevenagel condensation of 8 with 3-substituted-phenyl-2-thioxothiazolidin-4-one (3a-31) and 3-(5-substituted phenyl)1,3,4-thiadiazol-2-yl)-2-thioxothiazolidin-4-one (5a-5f), respectively. The IR spectra of the hybrids presented bands for the $\mathrm{C}=\mathrm{O}$ (carbonyl) and $\mathrm{C}=\mathrm{S}$ groups of rhodanine moiety around 1713.58-1678.41 $\mathrm{cm}^{-1}$ and $1247.91-1221.96 \mathrm{~cm}^{-1}$, while the most prominent band appeared around 1605.94-1567.83 $\mathrm{cm}^{-1}$ due to $\mathrm{C}=\mathrm{CH}$ (arylidene) group. This observation was further substantiated by the ${ }^{1} \mathrm{H}-\mathrm{NMR}$ of compounds $9 \mathrm{a}-9 \mathrm{l}$ and 10a-10f, displaying singlet peak resonating around $\delta 8.06-7.91 \mathrm{ppm}$ and $\delta$ 9.16-9.02 $\mathrm{ppm}$, accounting for the $\mathrm{CH}=\mathrm{C}$ (arylidene) proton at $3^{\text {rd }}$ position of the carbazole nucleus. The disappearance of a distinct singlet at around $\delta$ 4.4-4.17 ppm for the $-\mathrm{CH}_{2}$ - (methylene) protons of the rhodanine ring evidently confirmed the formation of the desired final compounds. Moreover, the formation of final derivatives was further confirmed by recording some of their mass spectra (HR-MS) which displayed positive correlation with their anticipated molecular weights. IR, ${ }^{1} \mathrm{H}-\mathrm{NMR}$, ${ }^{13} \mathrm{C}-\mathrm{NMR}$ and HR-MS spectra are provided in the supporting information.

These newly synthesized compounds were evaluated against $\mathrm{H}_{37} \mathrm{Rv}$ for their anti-TB potential and InhA inhibition as well as toxicity profile on mammalian cells. For our previously reported compounds, ${ }^{10}$ the InhA inhibition activity was determined and the data is presented in Table 1.

Table 1.

InhA inhibition data of the compounds $\mathbf{3}$ and $\mathbf{6 a - 0}$

\begin{tabular}{ll|ll}
\hline $\begin{array}{l}\text { Compound } \\
\text { code* }\end{array}$ & $\begin{array}{l}\text { InhA inhibition } \\
(\% \text { at } 50 \mu \mathrm{M})\end{array}$ & Compound code* & $\begin{array}{l}\text { InhA inhibition } \\
(\% \text { at } 50 \mu \mathrm{M})\end{array}$ \\
\hline 3 & 45 & $6 \mathrm{~h}$ & 10 \\
$6 \mathrm{a}$ & 23 & $6 \mathrm{i}$ & 43 \\
$6 \mathrm{~b}$ & 23 & $6 \mathrm{j}$ & 27 \\
$6 \mathrm{c}$ & $6 \mathrm{k}$ & $\mathrm{NI}$ \\
$6 \mathrm{~d}$ & 42 & $6 \mathrm{l}$ & 42 \\
$6 \mathrm{e}$ & Not soluble & $6 \mathrm{~m}$ & 58 \\
$6 \mathrm{f}$ & 10 & $6 \mathrm{n}$ & 42 \\
$6 \mathrm{~g}$ & 30 & $6 \mathrm{o}$ & 30 \\
\hline
\end{tabular}

*Synthesis, characterization, $M$. tuberculosis $\mathrm{H}_{37} \mathrm{Rv}$ and cytotoxicity evaluations results of compounds 3 and $\mathbf{6 a - 0}$ were reported in our earlier publication. ${ }^{10}$ 
Anti-TB (in vitro) activity of all the final compounds was carried out at the Infectious Disease Research Institute (IDRI) within the National Institute of Allergy and Infectious Diseases (NIAID) screening program, Bethesda, MD, USA. All the hybrids were screened against the virulent strain of $M$. tuberculosis $\mathrm{H}_{37} \mathrm{Rv}$ grown under aerobic conditions by using a dual read-out (OD590 and fluorescence) assay procedure. ${ }^{31-34}$ The results of the antimycobacterial activity (MIC values) are presented in Table 2.

Table 2.

Antitubercular evaluation of 9a-9l and 10a-10f against $M t b \mathrm{H}_{37} \mathrm{Rv}$ and InhA along with cytotoxicity data.

\begin{tabular}{|c|c|c|c|}
\hline Compound & $\begin{array}{c}\text { M. tuberculosis } \\
\mathbf{H}_{37} \mathbf{R v}^{\mathbf{a}}\end{array}$ & $\begin{array}{c}\text { InhA inhibition (\% at } \\
\qquad 50 \mu M)\end{array}$ & $\begin{array}{l}\text { Cytotoxicity } \\
\text { IC }_{50}{ }^{b}(\mu \mathrm{M})\end{array}$ \\
\hline $9 \mathbf{a}$ & $>100$ & 6 & 235.2 \\
\hline $9 \mathrm{~b}$ & $>100$ & $\mathrm{NI}$ & 167.2 \\
\hline $9 c$ & $50\left(\mathrm{IC}_{50}=50 \mu \mathrm{M}\right)$ & 15 & $260.9(5.2)^{\mathrm{c}}$ \\
\hline 9d & $>100$ & 24 & 185.0 \\
\hline $9 e$ & $>100$ & $91(54 \%$ at $5 \mu \mathrm{M}) \mathrm{IC}_{50}=2.82$ & 262.7 \\
\hline 9f & $>100$ & 52 & 277.2 \\
\hline $9 g$ & $>100\left(\mathrm{IC}_{50}=25 \mu \mathrm{M}\right)$ & $62(10 \%$ at $5 \mu \mathrm{M})$ & $289.3(11.6)^{\mathrm{c}}$ \\
\hline $9 h$ & $>100$ & $67(12 \%$ at $5 \mu \mathrm{M})$ & 210.1 \\
\hline $9 \mathrm{i}$ & $20\left(\mathrm{IC}_{50}=20 \mu \mathrm{M}\right)$ & 13 & $296.4(14.8)^{\mathrm{c}}$ \\
\hline $9 \mathbf{i}$ & $>100$ & $\mathrm{NI}$ & 222.0 \\
\hline $9 k$ & $>100\left(\mathrm{IC}_{50}=75 \mu \mathrm{M}\right)$ & 32 & $239.5(3.2)^{\mathrm{c}}$ \\
\hline 91 & $>100$ & NI & 212.8 \\
\hline $10 a$ & $>100$ & $\mathrm{NI}$ & 208.1 \\
\hline 10b & $>100$ & 37 & 245.0 \\
\hline $10 \mathrm{c}$ & $>100$ & 53 & 239.0 \\
\hline 10d & $>100$ & 52 & 165.2 \\
\hline $10 \mathrm{e}$ & $>100$ & Not soluble & 192.7 \\
\hline $10 f$ & $>100$ & 34 & 258.3 \\
\hline GEQ & $>\mathbf{5 0}$ & 88 & --- \\
\hline
\end{tabular}

${ }^{a}$ MIC at which $M$. tuberculosis $\mathrm{H}_{37} \mathrm{Rv}$ growth was completely inhibited and is derived from the inflection point of the fitted curve to the lower asymptote (zero growth); ${ }^{\mathbf{b}}$ Cytotoxicity activity $\left(\mathrm{IC}_{50}\right)$ was determined on mammalian Vero cell line. $\mathrm{NI}=$ No inhibition; ${ }^{\mathrm{c}}$ Selectivity index determined as the ratio cytotoxicity/ $\mathrm{IC}_{50}\left(\mathrm{H}_{37} \mathrm{Rv}\right)$. The compounds presenting $\mathrm{IC}_{50}$ values $>100$ were not considered for the selectivity index calculation.

Among the tested series, compound 9i $(\mathrm{MIC}=20 \mu \mathrm{M})$ with coumarin ring on rhodanine nucleus displayed the best antimycobacterial activity with an $\mathrm{IC}_{50} 20 \mu \mathrm{M}$, followed by $9 \mathrm{~g}$ bearing the hydroxyl $(\mathrm{OH})$ group on the $2^{\text {nd }}$ position of aromatic nucleus indicated 
good activity with $\mathrm{IC}_{50} 25 \mu \mathrm{M}$, while 9c $(\mathrm{MIC}=50 \mu \mathrm{M})$, the 3,4-dimethoxy groups on aromatic ring exhibited moderate inhibitory activity with an $\mathrm{IC}_{50} 50 \mu \mathrm{M}$. The remaining compounds in this series with halogen groups on the aromatic ring were found to be least active. According to literature reprots an optimum lipophilicity is required to facilitate the entrance of the molecules through lipid-enriched mycobacterial membrane. ${ }^{35}$ Hence, clog $\mathrm{P}$ values of the most active compounds were calculated and the results presented no conclusive outcome. However based on the calculated clog $\mathrm{P}$ values, 9e was one of the most polar compounds due to the presence of carboxylic functional group, which could be responsible for no cell permeability in the cell-based anti-mycobacterial inhibition. While compounds 9c, 9g, 9i and 9k displayed favorable antimycobacterial activity, which could be attributed to the presence of electron releasing lipophilic functionalities like dimethoxy, hydroxy and the bulkier coumarine substituents, respectively. In addition, the functional group on the aromatic ring attached to the rhodanine ring contributed to the lipophilicity and binding interactions. Thus, poor antimycobacterial activity of compound $\mathbf{9 e}$ could be attributed to the hydrophilic, polar carboxylic functional group on the aromatic ring of the rhodanine moiety.

To determine the potential InhA inhibition activity of these hybrids, an enzyme assay was carried out in triplicate as per previously reported protocols. ${ }^{36}$ Assays were performed using 2-trans-dodecenoyl-CoA as a substrate analogue and the percentage inhibition was measured considering the conversion of the NADH into its oxidized form NAD ${ }^{+}$at $340 \mathrm{~nm}$. GEQ compound, a well-known inhibitor of InhA, was used as reference ${ }^{37,38}$ and all the hybrid molecules were tested at $50 \mu \mathrm{M}$ in triplicate. The InhA inhibition activity data and the cytotoxicity data of the new hybrids (9a-91 and 10a-10f) are represented in Table 2. From the InhA inhibition data, compounds $9 \mathbf{e}, \mathbf{9 g}$ and $\mathbf{9 h}$ exhibited higher (above 60\%) inhibition at 50 $\mu \mathrm{M}$ i.e. $91 \%, 62 \%$ and $67 \%$, respectively. For these three compounds, the assay was performed at $5 \mu \mathrm{M}$ concentration and specifically, 9e (54\% inhibition) presented activity above $50 \%$. The $\mathrm{IC}_{50}$ value of $9 \mathrm{e}$ was determined using the 4-parameter curve-fitting software XLFit (IDBS) and it was observed at higher potency of $2.82 \mu \mathrm{M}$ (Fig. 2). Compound 9e showed a very interesting activity against InhA enzyme but a very poor activity against Mtb $\mathrm{H}_{37} \mathrm{Rv}$ strain which could be due to the efflux pumps action or membrane permeability. 


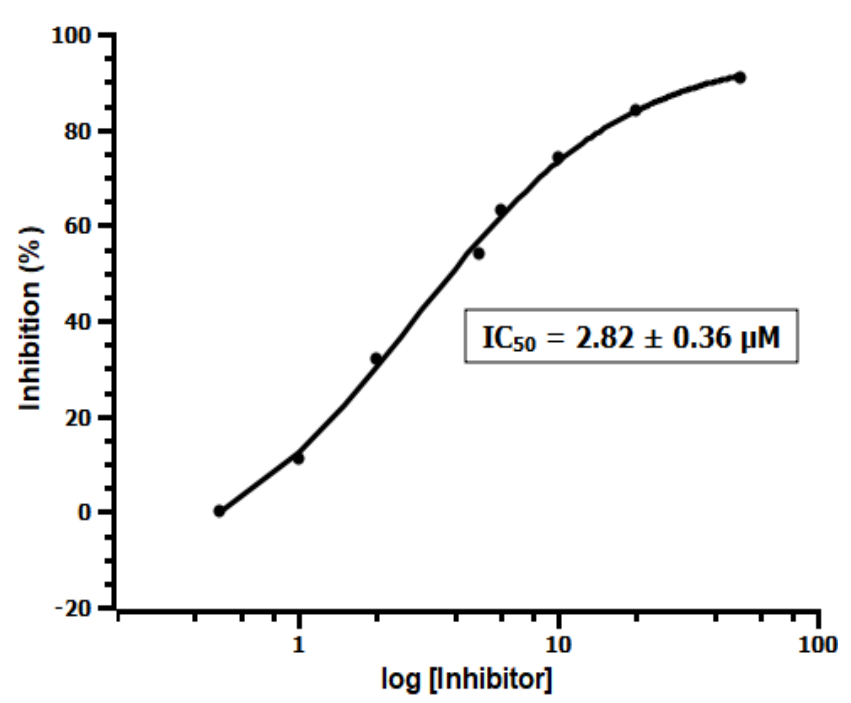

Fig. 2. Determination of $\mathrm{IC}_{50}$ of compound $9 \mathrm{e}$ against $\mathrm{InhA}$.

All the final compounds were further evaluated for cytotoxicity on a mammalian Vero cell line. ${ }^{39}$ The cellular conversion of MTT [3-(4,5-dimethylthiazo-2-yl)-2,5-diphenyltetrazolium bromide] into a formazan product was used to evaluate cytotoxicity. After $72 \mathrm{~h}$ of exposure, the viability of the cells was assessed using the Promega Cell Titre 96 nonradioactive cell proliferation assay. The $\mathrm{IC}_{50}$ values were determined and are presented in Table 2. All the novel carbazolyl substituted derivatives displayed an interesting cytotoxicity profile with $\mathrm{IC}_{50}$ values ranging from 165.2-296.4 $\mu \mathrm{M}$. Among the series, 9i displayed least cytotoxicity $\left(\mathrm{IC}_{50}=296.4 \mu \mathrm{M}\right)$ followed by $9 \mathrm{c}, 9 \mathrm{e}, \mathbf{9 f}, \mathbf{9 g}$ and $10 \mathrm{f}\left(\mathrm{IC}_{50}>250 \mu \mathrm{M}\right)$. None of the final compounds exhibited substantial cytotoxic activity against the human Vero cell line at concentrations $<100 \mu \mathrm{M}$. These results are particularly important, as the compounds with their increased cyto-viability could be very attractive in developing new chemical entities (NCEs) to treat chronic infectious diseases such as TB, principally due to long treatment regimen required. Thus, there is an urgent need to develop new anti-TB agents with a high margin of safety.

In order to understand the ligand-enzyme interactions between compound $9 \mathbf{e}$ and InhA (PDB ID: 4TZK) ${ }^{40}$ active-site, a molecular docking study was performed using Glide ${ }^{41}$ program of Schrodinger. A Grid was generated and validated by docking the existing cocrystallized ligand in PDB 4TZK. The docking results exhibited similar pose besides crucial molecular interactions with the active-site residues as reported in the literature. The docked complex presented a characteristic, strong hydrogen bonding interaction between the carbonyl oxygen $(\mathrm{C}=\mathrm{O})$ of pyrrolidinone and $-\mathrm{OH}$ group of Tyr158. Further, a distinctive halogen bond was observed between the chlorine and $-\mathrm{HN}$ of Gly104 as presented in original PDB report. All crucial molecular interactions were reproduced that subsequently validated 
the protocols for further docking of the synthesized hybrid compounds into the active-site of the protein. Interestingly, the most active compound 9e exhibited essential interactions with InhA. The carbazole moiety of $9 \mathrm{e}$ buried inside the hydrophobic pocket of the protein core consisting of Met103, Gly104, Phe149, Pro193, Met199, Leu207, Ala211 and Ile215, while the rhodanine nucleus stabilized within the active-site by interacting with hydrophobic residues (Phe97 and Ala198) as well as exhibiting a weak hydrogen bond with Met98 $(2.77 \AA)$. The carboxylic acid group in 9e contributed towards the orientation of the entire ligand in the active-site of the enzyme by orienting itself into the solvent accessible area of the protein cavity. Similarly, the phenyl ring in 9e provided the stability to the ligand inside the active-site through hydrophobic interactions involving residues of Ile16, Phe41, Phe97 and Ala198. The molecular interactions of $9 \mathbf{e}$ with the active-site residues are presented in Fig. 3.



Fig. 3. The docked pose (thick-tube model, magenta colour) of compound 9e into the activesite showing crucial interactions.

To confirm the validity and stability of the proposed docking results, the dynamic stability of 9e within the enzyme was examined in the complex over 10 ns duration by using Maestro-Desmond Tool. ${ }^{42,43}$ The post dynamic analyses were carried out to understand the stability of the ligand-protein complex which was determined by average root mean square deviation (RMSD). ${ }^{44,45}$ Over the period of time, RMSD-P, RMSF-P and RMSD-L ( $\mathrm{P}=$ Protein, L=Ligand) were scrutinized to support our docking study. The initial pose of ligand-protein complex was considered as a reference frame to calculate these properties. The RMSD-P was basically calculated to understand the large-scale movements in the protein when the ligand is present in the active-site. The RMSD-P for the complex was observed in the range of 0.6 to $1.8 \AA$. This observation suggested that $9 \mathbf{e}$ in the active-site of the protein has not influenced the stability of protein back-bone throughout the simulation run. Further, 
to confirm the binding stability of $9 \mathbf{e}, \mathrm{RMSD}-\mathrm{L}$ was computed and observed in the range of 0.2 to $1.2 \AA$ which indicated the good stability of the ligand with respect to the protein and its binding pocket. For the entire duration of the simulation run, no major deviation in RMSD was observed (Fig. 4a). The structural integrity of the protein and the residual mobility of the ligand were quantified in terms of RMSF-P. For almost all residues including loop residues except the terminal residues of the protein, the RMSF-P was below $2.05 \AA$ whereas the terminals showed the RMSF-P was up to $3.3 \AA$ (Fig. 4b). In the protein-ligand stability, the interactions were also evaluated over a period of the simulation time, which indicated that $\mathrm{H}$ bond was maintained only for $10 \%$ of the simulation time, either with Met98 or Gln100 with the $\mathrm{H}$-bond distance $\leq 2.5 \AA$ and donor angle $\geq 120^{\circ}$ and acceptor angle $\geq 90^{\circ}$ indicating that $\mathrm{H}$-bond interactions in the docking study was weak. Further, for $76 \%$ of the simulation time, Tyr158 residue was involved in hydrophobic interactions which played a valid role in the stability of ligand-protein complex (Fig. S1). The ligand RMSF was observed in between 1.0 to $2.5 \AA$ explaining the range of ligand atom positions over the simulation time period. The other ligand parameters like rGyr, MolSA, SASA and PSA were observed in the acceptable range (Fig. S2).
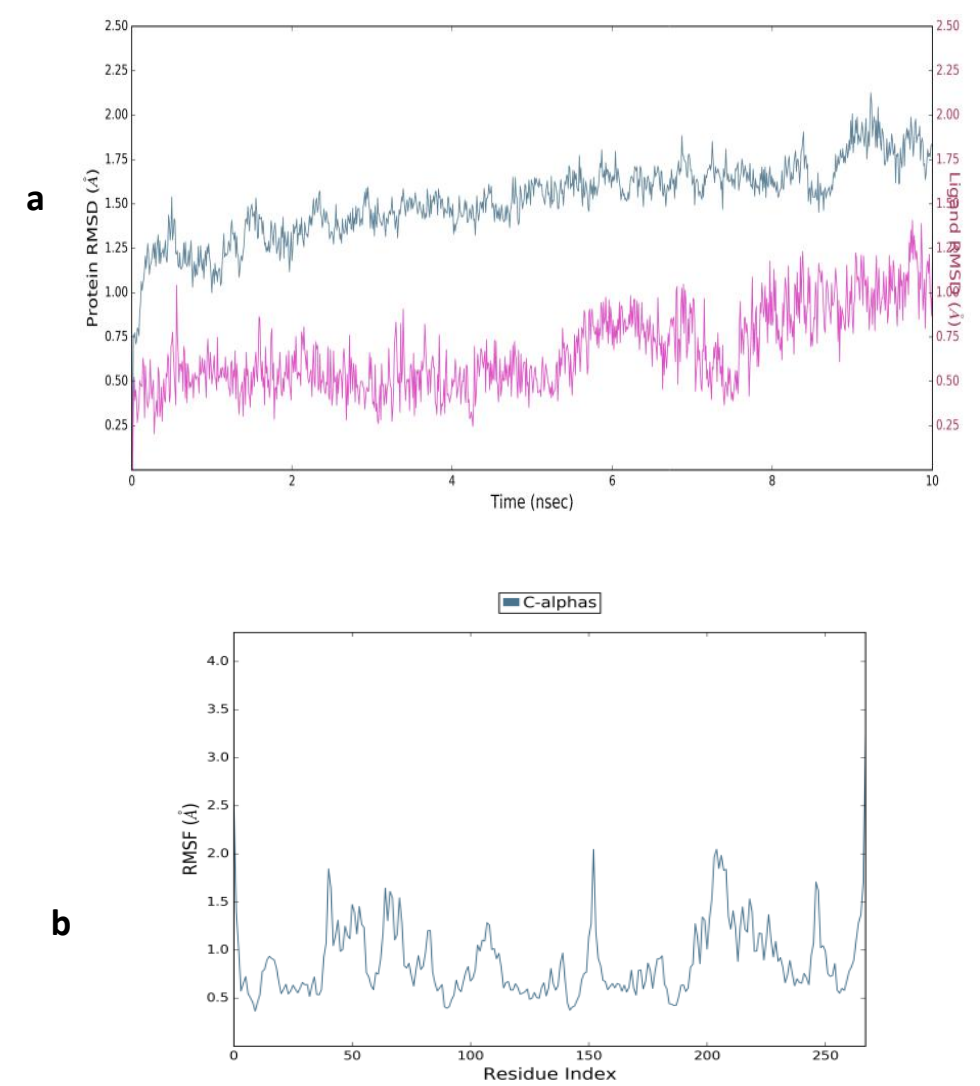

Fig. 4. (a) Protein and Ligand (9e) RMSD, blue line indicates protein RMSD whereas pink line indicates ligand RMSD; (b) Protein RMSF over the simulation time of $10 \mathrm{~ns}$. 
In summary, novel carbazole hybrid derivatives were synthesized and evaluated for their anti-TB and InhA inhibition activity. Compounds $9 \mathbf{c}, 9 g, 9 \mathbf{i}$ and $9 k$ exhibited the moderate anti-TB activity considering the $\mathrm{IC}_{50}$ value below $100 \mu \mathrm{M}$ against the virulent $\mathrm{TB}$ cell line $\mathrm{H}_{37} \mathrm{Rv}$. Compound 9e showed promising InhA inhibition with an $\mathrm{IC}_{50}$ value of 2.82 $\mu \mathrm{M}$. To understand the molecular interactions of the most active compound 9e with the active-site, molecular docking was carried out which was further supported by the molecular dynamics. The cytotoxicity $\left(\mathrm{IC}_{50}\right)$ assessment against the human Vero cell line using MTT assay demonstrated that the newly synthesized compounds were non-cytotoxic. These exciting results have led to the identification of carbazole hybrids as a new class of InhA direct inhibitor and will further assist the scientific community to develop safer yet potential anti-TB agents, which is the need of the hour.

\section{Supporting Information}

All experimental data, spectral images and figures associated with molecular dynamics are provided in supporting information.

\section{Disclosure statement}

Authors hereby declare that there are no financial/commercial conflicts of interest.

\section{Acknowledgements}

Authors are grateful to Discipline of Pharmaceutical Sciences, College of Health Sciences, University of KwaZulu-Natal (UKZN), Durban, South Africa for providing access to necessary facilities. Author BC gratefully acknowledge National Research Foundation (NRF), South Africa (SA) for the research funding in the form of NRF-Innovation PostDoctoral Research Fellowship (Grant No. 99546). RK is also thankful to NRF-SA for funding this project (Grant No. 103728 and 112079). Authors also sincerely thank Centre for High Performance Computing (CHPC), Cape Town, South Africa for computational resources. Authors express heartfelt thanks to Mr. Dilip Jagjivan and Dr. Caryl Janse Van Rensburg (UKZN, South Africa) for their assistance in NMR and HR-MS experiments.

\section{References}

1. World Health Organization.

http://www.who.int/tb/publications/global_report/MainText_13Nov2017.pdf

2. World Health Organization. http://www.who.int/tb/areas-of-work/tb-hiv/en/ 
3. Duan, X.; Xiang. X.; Xie, J. Crucial components of Mycobacterium type II fatty acid biosynthesis (Fas-II) and their inhibitors. FEMS Microbiol. Lett. 2014, 360, 87-99.

4. Fernandes, G. F. S.; Salgado, H. R. N.; Santos, J. L. Isoniazid: A review of characteristics, properties and analytical methods. Crit. Rev. Anal. Chem. 2017, 47, 298-308.

5. Campbel, I. A. First randomised trial of treatments for pulmonary disease caused by M. avium intracellulare, $M$. malmoense, and $M$. xenopi in HIV negative patients: rifampicin, ethambutol and isoniazid versus rifampicin and ethambutol. Thorax 2001, $56,167-172$.

6. Chollet, A.; Maveyraud, L.; Lherbet, C.; Bernardes-Génisson, V. An overview on crystal structures of InhA protein: Apo-form, in complex with its natural ligands and inhibitors. Eur. J. Med. Chem. 2018, 146, 318-343.

7. Suarez, J.; Ranguelova, K.; Jarzecki, A. A.; Manzerova, J.; Krymov, V; Zhao, X.; Yu, S.; Metlitsky, L.; Gerfen G. J.; Magliozzo, R. S. An oxyferrous heme/proteinbased radical intermediate is catalytically competent in the catalase reaction of Mycobacterium tuberculosis catalase-peroxidase (KatG). J. Biol. Chem. 2009, 284, 7017-7029.

8. Vannelli, T. A.; Dykman, A.; Montellano, P. R. O. The Antituberculosis drug Ethionamide is activated by a flavoprotein monooxygenase. J. Biol. Chem. 2002, 277, 12824-12829.

9. Timmins, G. S.; Master, S.; Rusnak, F.; Deretic, V. Nitric oxide generated from isoniazid activation by KatG: Source of nitric oxide and activity against Mycobacterium tuberculosis. Antimicrob. Agents Chemother. 2004, 48, 3006-3009.

10. Shaikh, M. S.; Palkar, M. B.; Patel, H. M.; Rane, R. A.; Alwan, W. S.; Shaikh, M. M.; Shaikh, I. M.; Hampannavar, G. A.; Karpoormath, R. Design and synthesis of novel carbazolo-thiazoles as potential anti-mycobacterial agents using a molecular hybridization approach. RSC Adv. 2014, 4, 62308-62320.

11. Knolker, H. J.; Reddy, K. R. Isolation and synthesis of biologically active carbazole alkaloids. Chem. Rev. 2002, 102, 4303-4427.

12. Tomasic, T.; Masic, L. P. Rhodanine as a privileged scaffold in drug discovery. Curr. Med. Chem. 2009, 16, 1596-1629.

13. Muhammad, S. A.; Ravi, S.; Thangamani, A.; Chandrasekaran, B.; Ramesh, M. Synthesis, antiproliferative activity and docking study of novel rhodanine derivatives as Bcr-Abl T1351 inhibitors. Res. Chem. Intermed. 2017, 43, 5871-5887. 
14. Song, M. X.; Li S. H.; Peng, J.Y.; Guo, T.T.; Xu W.H.; Xiong, S.F.; Deng, X. Q. Synthesis and bioactivity evaluation of $N$-arylsulfonylindole analogs bearing a rhodanine moiety as antibacterial agents. Molecules 2017, 22, 970.

15. Patpi, S. R.; Pulipati, L.; Yogeeswari, P.; Sriram, D.; Jain, N.; Sridhar, B.; Murthy, R.; Devi T, A.; Kalivendi, S. V.; Kantevari, S. Design, synthesis, and structure-activity correlations of novel dibenzo[b,d]furan, dibenzo[b,d]thiophene, and $N$-methyl carbazole clubbed 1,2,3-triazoles as potent inhibitors of Mycobacterium tuberculosis. J. Med. Chem. 2012, 55, 3911-3922.

16. Baell, J. B.; Holloway, G. A. New substructure filters for removal of pan assay interference compounds (PAINS) from screening libraries and for their exclusion in bioassays. J. Med. Chem. 2010, 53, 2719-2740.

17. Tomašić, T.; Mašič, L. P. Rhodanine as a scaffold in drug discovery: A critical review of its biological activities and mechanisms of target modulation. Expert Opin. Drug Discov. 2012, 7, 549-560.

18. Babaoglu, K.; Simeonov, A.; Irwin, J. J.; Nelson, M. E.; Feng, B.; Thomas, C. J.; Cancian, L.; Costi, M. P.; Maltby, D. A.; Jadhav, A.; Inglese, J.; Austin, C. P.; Shoichet, B. K. Comprehensive mechanistic analysis of hits from high-throughput and docking screens against beta-lactamase. J. Med. Chem. 2008, 51, 2502-2511.

19. Sink, R.; Gobec, S.; Pecar, S.; Zega. A. False positives in the early stages of drug discovery. Curr. Med. Chem. 2010, 17, 4231-4255.

20. Mendgen, T.; Steuer, C.; Klein, C. D. Privileged scaffolds or promiscuous binders: a comparative study on rhodanines and related heterocycles in medicinal chemistry. $J$. Med. Chem. 2012, 55, 743-753.

21. Dahlin JL, Baell J, Walters MA. Assay Interference by Chemical Reactivity. 2015 Sep 18. In: Sittampalam GS, Coussens NP, Brimacombe K, et al., editors. Assay Guidance Manual [Internet]. Bethesda (MD): Eli Lilly \& Company and the National Center for Advancing Translational Sciences; 2004-. Available from: https://www.ncbi.nlm.nih.gov/books/NBK326709/).

22. Kaminskyy, D.; Kryshchyshyn, A.; Lesyk, R. Recent developments with rhodanine as a scaffold for drug discovery. Expert Opin. Drug Discov. 2017, 12, 1233-1252.

23. Dorkhan, M.; Frid, A. A review of pioglitazone $\mathrm{HCl}$ and glimepiride in the treatment of type 2 diabetes. Vasc Health Risk Manag. 2007, 3, 721-731. 
24. Mousavi, S. M.; Zarei, M.; Hashemi, S. A.; Babapoor, A.; Amani, A. M. A conceptual review of rhodanine: current applications of antiviral drugs, anticancer and antimicrobial activities. Artificial Cells, Nanomed Biotechnol. 2019, 47, 1132-1148.

25. Liu, H.; Sun, D.; Du, H.; Zheng, C.; Li, J.; Piao, H.; Li, J.; Sun, L. Synthesis and biological evaluation of tryptophan-derived rhodanine derivatives as PTP1B inhibitors and anti-bacterial agents. Eur. J. Med. Chem. 2019, 172, 163-173.

26. Subhedar, D. D.; Shaikh, M. H.; Shingate, B. B.; Nawale, L.; Sarkar, D.; Khedkar, V. M.; Khan, F. A. K.; Sangshetti, J. N. Quinolidene-rhodanine conjugates: Facile synthesis and biological evaluation. Eur. J. Med. Chem. 2017, 125, 385-399.

27. Zhang, D.; Marko ulides, M. S.; Stepanovs, D.; Rydzik, A. M.; El-Hussein, A.; Bon, C.; Kamps, J. J. A. G.; Umland, K.-D.; Collins, P. M.; Cahill, S. T.; Wang, D. Y.; Delft, F. Brem, J.; McDonough, M. A.; Schofield, C. J. Structure activity relationship studies on rhodanines and derived enethiol inhibitors of metallo- $\beta$-lactamases. Bioorg. Med. Chem. 2018, 26, 2928-2936.

28. Sun, L.; Wang, P.; Xu, L.; Gao, L.; Li, J.; Piao, H. Discovery of 1,3-diphenyl-1Hpyrazole derivatives containing rhodanine-3-alkanoic acid groups as potential PTP1B inhibitors. Bioorg. Med. Chem. Lett. 2019, 29, 1187-1193.

29. Wu, Y.; Ding, X. Xu, S.; Yang, Y.; Zhang, X.; Wang, C.; Lei, H.; Zhao, Y. Design and synthesis of biaryloxazolidinone derivatives containing a rhodanine or thiohydantoin moiety as novel antibacterial agents against Gram-positive bacteria. Bioorg. Med. Chem. Lett. 2019, 29, 496-502.

30. He, X. Y.; Zou, P.; Qiu, J.; Hou, L.; Jiang, S.; Liu, S.; Xie, L. Design, synthesis and biological evaluation of 3-substituted 2,5-dimethyl- $N$-(3-(1H-tetrazol-5-yl)phenyl) pyrroles as novel potential HIV-1 gp41 inhibitors. Bioorg. Med. Chem. 2011, 19, 6726-6734.

31. Mc, Farland, J. Nephelometer: An instrument for estimating the number of bacteria in suspensions used for calculating the opsonic index and for vaccines. J. American Med. Assoc. 1907, XLIX, 1176-1178.

32. Ollinger, J.; Bailey, M. A.; Moraski, G. C.; Casey, A.; Florio, S.; Alling, T.; Miller, M. J.; Parish, T. A dual read-out assay to evaluate the potency of compounds active against Mycobacterium tuberculosis. PLoS One 2013, 8, e60531.

33. Zelmer, A.; Carroll, P.; Andreu, N.; Hagens, K.; Mahlo, J.; Redinger, N.; Robertson, B. D.; Wiles, S.; Ward, T. H.; Parish, T.; Ripoll, J.; Bancroft, G. J.; Schaible, U. E. A new in vivo model to test anti-tuberculosis drugs using fluorescence imaging. $J$ 
Antimicrob. Chemother. 2012, 67, 1948-1960.

34. Hampannavar, G. A.; Karpoormath, R.; Palkar, M. B.; Shaikh, M. S.;

Chandrasekaran, B. Dehydrozingerone inspired styryl hydrazine thiazole hybrids as promising class of antimycobacterial agents. ACS Med. Chem. Lett. 2016, 7, 686691.

35. Navarrete-Vázquez, G.; Molina-Salinas, G. M.; Duarte-Fajardo, Z. V.; VargasVillarreal, J.; Estrada-Soto, S.; González-Salazar, F.; Hernández-Núñez, E.; SaidFernández, S. Synthesis and antimycobacterial activity of 4-(5-substituted-1,3,4oxadiazol-2-yl)pyridines. Bioorg. Med. Chem. 2007, 15, 5502-5508.

36. Chollet, A.; Mori, G.; Menendez, C.; Rodriguez, F.; Fabing, I.; Pasca, M. R.; Madacki, J.; Kordulakova, J.; Constant, P.; Quemard, A.; Bernardes-Génisson, V.; Lherbet, C.; Baltas, M. Design, synthesis and evaluation of new GEQ derivatives as inhibitors of InhA enzyme and Mycobacterium tuberculosis growth. Eur. J. Med. Chem. 2015, 101, 218-235.

37. Kuo, M. R.; Morbidoni, H. R.; Alland, D.; Sneddon, S. F., Gourlie, B.B.; Staveski, M. M., Leonard, M.; Gregory, J. S.; Janjigian, A.D.; Yee, C.; Musser, J. M.; Kreiswirth, B.; Iwamoto, H.; Perozzo, R.; Jacobs, W. R. Jr; Sacchettini, J.C.; Fidock, D. A. Targeting tuberculosis and malaria through inhibition of Enoyl reductase: compound activity and structural data J. Biol. Chem. 2003, 278, 20851-20859.

38. Matviiuk, T.; Madacki, J.; Mori, G.; Orena, B.S.; Menendez, C.; Kysil, A.; AndréBarrès, C.; Rodriguez, F.; Korduláková, J.; Mallet-Ladeira, S.; Voitenko, Z.; Pasca, M.R.; Lherbet, C.; Baltas, M. Pyrrolidinone and pyrrolidine derivatives: Evaluation as inhibitors of InhA and Mycobacterium tuberculosis. Eur. J. Med. Chem. 2016, 123, $462-475$.

39. Falzari, K.; Zhu, Z.; Pan, D.; Liu, H.; Hongmanee P.; Franzblau, S. G. In vitro and in vivo activities of macrolide derivatives against Mycobacterium tuberculosis. Antimicrob. Agents Chemother. 2005, 49, 1447-1454.

40. He, X.; Alian, A.; Stroud, R.; Ortiz de Montellano, P. R. Pyrrolidine carboxamides as a novel class of inhibitors of Enoyl-acyl carrier protein reductase from Mycobacterium tuberculosis. J. Med. Chem. 2006, 49, 6308-6323.

41. Schrödinger Release 2017-2: Glide, Schrödinger, LLC, New York, NY, 2017.

42. Tuckerman, M.; Berne, B. J.; Martyna, G. J. Reversible multiple time scale molecular dynamics. J. Chem. Phys. 1992, 97, 1990-2001.

43. Bowers, K. J.; Chow, E.; Xu, H.; Dror, R. O.; Eastwood, M. P.; Gregersen, B. A.; 
Klepeis, J. L.; Kolossvary, I.; Moraes, M. A.; Sacerdoti, F. D.; Salmon, J. K.; Shan, Y.; Shaw, D. E. Scalable algorithms for molecular dynamics simulations on commodity clusters. Proceedings of the ACM/IEEE Conference on Supercomputing (SC06), Tampa, Florida, 2006, November 11-17.

44. Chandrasekaran, B.; Muthusamy, R.; Tham, C. L.; Khathi, S. P.; Kozielski, F.; Cherukupalli, S.; Hampannavar, G. A.; Sayyad, N.; Soliman, M. E.; Karpoormath, R. Ligand- and structure-based in silico studies to identify kinesin spindle protein (KSP) inhibitors as potential anticancer agents, J. Biomol. Struc. Dyn. 2018, 36, 36873704.

45. Agrawal, N.; Skelton, A. A. Binding of 12-crown-4 with Alzheimer's A $\beta 40$ and A $\beta 42$ monomers and its effect on their conformation: insight from molecular dynamics simulations. Mol. Pharmaceutics 2018, 15, 289-299. 